\title{
Passivation of mild steel by sodium octylphosphonate in neutral aqueous solution ${ }^{1}$
}

\author{
Yu.I. Kuznetsov, A.A. Chirkunov, A.S. Gorbachev and N.P. Andreeva \\ A.N. Frumkin Institute of Physical Chemistry and Electrochemistry, Russian Academy \\ of Sciences, Leninsky pr. 31, Moscow, 119071 Russian Federation \\ E-mail:kunetsov@ipc.rssi.ru
}

\begin{abstract}
The effect of temperature, $\mathrm{pH}$ and exposure time on the passivating properties of sodium octylphosphonate (OP) have been investigated. It has been shown that passivation of steel in the presence of OP may occur without the formation of a surface oxide. It has been established by ellipsometry that adsorption of OP is described by a Frumkin isotherm both for oxidized and reduced steel surface, and that it is better adsorbed on reduced surface.
\end{abstract}

Keywords: passivation, adsorption, corrosion inhibitor, octylphosphonic acid.

Received: June 20, 2017. Published: June 28, 2017.

doi: $\underline{10.17675 / 2305-6894-2017-6-3-7}$

\section{Introduction}

Passivation of metals in aqueous solutions of organic corrosion inhibitors has been attracting the attention of researchers for a long time in connection with the search for effective substitutes for environmentally hazardous inorganic oxidants (chromates and nitrites) and further improvement of the protection of metals from corrosion in the atmosphere and in aqueous solutions [1-5]. The most attention in this aspect was paid to salts of carboxylic acids, and the possibility of adsorptive ("oxide-free") passivation of iron and low-carbon steel in a neutral aqueous solution was demonstrated for the first time for sodium phenylanthranilate [5]. The results of these long-term studies are summarized in a monograph [6] and in reviews [7-9].

The ability of inhibitors to transfer metals to a passive state depends both on the nature of the chemical compounds used and on the nature of the metal under protection. The inhibitor must be strongly adsorbed on the surface to provide its blocking and to transfer the metal potential to values corresponding to passivation.

The advantages of carboxylates as passivating agents are quite obvious, since they have an active functional group that provides a strong interaction with the substrate, as well as a hydrocarbon part that blocks the surface from the environment. It is logical to assume that structurally similar compounds with other functional groups can also exhibit high

\footnotetext{
${ }^{1}$ This study was carried out at A.N. Frumkin Institute of Physical chemistry and Electrochemistry of the Russian academy of sciences with support of the Russian Science Foundation (Grant No. 17-13-01413 "Fundamental principles of creation of ultrathin passivating organic films on metals for protection against atmospheric corrosion").
} 
inhibitory properties. Other classes of compounds may also have passivating properties, such as nitrogen-containing heterocyclic compounds, which are very effective in protection of copper and its alloys [10-13].

The passivating ability of phosphonates, which are probably the second in significance and practically used class of organic corrosion inhibitors for various steels in neutral media, has been studied less thoroughly.

This is partly due to the fact that the studies were focused on phosphonate chelating agents, i.e., polybasic and very hydrophilic acids known as effective scale inhibitors [14]. However, in soft aqueous solutions, such as neutral borate buffer, they usually reduce the critical passivation current density $\left(i_{\mathrm{p}}\right)$ of mild steel only in a narrow range of concentrations [6]. With increasing in their concentration in such solutions, inhibition can give way to stimulation of steel dissolution due to the formation of soluble complexes of phosphonic acid with iron cations. However, there are cases where di- and polyphosphonates containing hydrocarbon radicals with a relatively large number of carbon atoms $\left(n_{\mathrm{C}}\right)$ are able to passivate iron or mild steel.

E. Kalman et al. [15] found that the corrosion rate of iron in $0.1 \mathrm{M} \mathrm{NaClO}_{4}$ can be decreased by addition of diphosphonic acid $\mathrm{H}_{2} \mathrm{O}_{3} \mathrm{P}-\left(\mathrm{CH}_{2}\right)_{7}-\mathrm{PO}_{3} \mathrm{H}_{2}$. The corrosion potential $E_{\mathrm{c}}$ increased, suggesting that passivation of the electrode occurred. However, the passive state region was not detected on the anodic polarization curves.

Addition of the sodium salt of hexamethylenediamine-N,N, $\mathrm{N}^{\prime}, \mathrm{N}^{\prime}$-tetrakismethylphosphonic) acid (HMDTP) to water containing $30 \mathrm{ppm} \mathrm{NaCl}$ and $70 \mathrm{ppm} \mathrm{Na}_{2} \mathrm{SO}_{4}$ completely suppressed the corrosion of a rotating mild steel cylinder in a wide range of inhibitor concentrations $\left(C_{\text {in }}\right)$ [16]. However, the authors did not study the effect of these phosphonates on the kinetics of anodic dissolution of the electrode; without these studies, it is difficult to make final conclusions about the passivation of steel and especially about its mechanism.

As regards metal passivation, phosphonic acids are the most interesting objects that, similarly to carboxylates, contain hydrophobic components in the molecule and can form self-assembled layers on surfaces [17-22]. In addition to the passivating effect, treatment of a metal by phosphonic acids can impart hydrophobic properties to the surface [21] that can also play an important role in corrosion protection.

Additional information about the formation of self-assembled layers of alkylphosphonates and the mechanism of mild steel passivation by these compounds was obtained in [17-19, 22].

A study on the kinetics of the formation of self-assembled layers by alkylphosphonates and alkyldiphosphonates has shown that the self-assembly of a phosphonate layer takes rather a long time, up to several days. Alkylphosphonates can form a monomolecular adsorption layer to give a hydrophobic modified surface, whereas $\alpha, \omega$-diphosphonates form a thin polymolecular adsorption layer due to intermolecular interaction between phosphono groups [17]. 
A study of the modification of the surface of passive iron with octylphosphonic acid showed [18] that preliminary oxide passivation of iron (in borate buffer with $\mathrm{pH}$ 8.4) makes the phosphonate layer more stable. Mössbauer spectroscopy showed that if the phosphonate layer is formed on passive iron, the oxide film becomes thinner, which is a consequence of the appearance of iron phosphonate in the protective layer.

Using a borate buffer with $\mathrm{pH} 7.3$ as a background solution, I.D. Zartsyn et al. [19] found that sodium dodecylphosphonate (DDP) decreased the $i_{\mathrm{p}}$ of mild steel St3 twofold at $C_{\text {in }}=5 \mathrm{mmol} / 1$ but a further increase in this concentration affects $i_{\mathrm{p}}$ insignificantly. However, if DDP added to the solution at a cathodic polarization potential of $E=-0.65 \mathrm{~V}$ where the original охideв is removed from the electrode surface, when polarization was disabled, the steel spontaneously passivated in 10 minutes, i.e., $E_{\mathrm{c}}$ increased by $0.4 \mathrm{~V}$. In this case no oxide reduction wave was observed during galvanostatic polarization of the electrode after exposure of the latter in the passive range of potentials. Using FT-IR reflection spectroscopy, they showed that the maximum DDP adsorption occurs if the cathodic reduction of the steel surface is carried out under deaerated conditions. The authors suggest that passivation of the steel electrode with oxide-free surface is due to DDP chemisorption, though no direct evidence of this fact has been obtained to date.

We also investigated the anodic behavior of mild steel in chloride-containing borate buffer at $\mathrm{pH} 7.4$ in the presence of sodium salts of monoalkylphosphonic acids with a smaller number of carbon atoms, $n_{\mathrm{C}}=7-10$ [14]. Sodium octylphosphonate (OP) demonstrated the highest passivating ability among these compounds, so we continued to study its protective effect in this paper.

\section{Experimental}

A borate buffer with $\mathrm{pH} 7.4$ containing $0.01 \mathrm{M} \mathrm{NaCl}$ to increase its corrosivity was used as the background solution. The electrodes were made of mild steel with the following composition (\%): $\mathrm{C} \leq 0.18, \mathrm{Mn} \leq 0.5 ; \mathrm{Si} \leq 0.2 ; \mathrm{P} \leq 0.04 ; \mathrm{S} \leq 0.05 ; \mathrm{Cu} \leq 0.3 ; \mathrm{As} \leq 0.08$. Polarization curves of mild steel were obtained in a glass cell with separated electrode spaces by means of a PI 50-1.1 potentiostat. Potentials of mild steel $(E)$ were measured relative to silver chloride electrode and converted to the normal hydrogen scale. A platinum counter electrode was used. After removal of the air formed oxide film by cathodic polarization of the electrode $(E=-0.65 \mathrm{~V}, 15 \mathrm{~min})$, polarization was turned off until a free corrosion potential $E_{\mathrm{c}}$ was established. Then, a solution of the inhibitor being studied was injected while maintaining the same potential value. After stabilization of a new $E_{\mathrm{c}}$ value, an anodic polarization curve was recorded under potentiodynamic conditions at $0.2 \mathrm{mV} / \mathrm{s}$.

A mild steel electrode was used for ellipsometric measurements. Adsorption was measured on a RR2000 manual ellipsometer in a cell designed for simultaneous electrochemical and ellipsometric studies [23]. A helium-neon laser with $\lambda=640 \mathrm{~nm}$ served as the radiation source. The angle of incidence was $68.5^{\circ}$ relative to the sample 
surface. Before the measurements, the air formed oxide film was removed by cathodic polarization $(E=-0.65 \mathrm{~V}, 20 \mathrm{~min})$. The completeness of oxide reduction was judged by achievement of constant ellipsometric angles $\Delta$ and $\Psi$ with time. In the study of inhibitor adsorption on reduced steel surface, portions of the inhibitor were added to solution at the same potential, because under these conditions the metal does not undergo dissolution, while hydrogen evolution occurs relatively slowly and does not create significant barriers to $\Delta$ and $\Psi$ measurements. Every new portion of the inhibitor was added only after constant ellipsometric angles were established. As a rule, establishing the equilibrium takes $1.5-2.0 \mathrm{~h}$ at each concentration. In the study of adsorption on oxidized surface, after removal of the primary oxide film the potential was abruptly shifted to $E=0.20 \mathrm{~V}$ and the electrode was kept for $2 \mathrm{~h}$ at this potential. As shown previously [24, 25], the ellipsometric parameters do not change further due to oxide growth after such exposure, and this allows us to study adsorption on a stable surface oxide. For this purpose, a concentrate of the organic compound being studied was injected into the solution and the changes in ellipsometric angles versus concentration or time were recorded.

In the calculation of the isotherms, we assumed that the degree of coverage $\Theta=1$ corresponds to the plateau on the plot of $(-\delta \Delta) v s . \log C$. To choose the adsorption isotherms and calculate the adsorption characteristics of the inhibitors, we estimated the adequacy of description of the plots by the following equations:

Langmuir equation

Frumkin equation

Temkin equation

$$
B C=\Theta /(1-\Theta)
$$

where $B$ is the adsorption constant that is related to the free energy of adsorption $\left(-\Delta G_{\mathrm{a}}^{0}\right)$ by the relationship:

$$
B=\left[\exp \left(-\Delta G_{\mathrm{a}}^{0} / R T\right)\right] / 55.5 ;
$$

$a$ is the attraction constant characterizing the interaction between the particles of the adsorbate; and $f$ is the factor of surface energetic inhomogeneity characterizing the change in enthalpy of adsorption with the degree of filling.

To select the equation of the adsorption isotherm, a statistical evaluation of the adequacy of the suggested equations to the experimental results by Fisher's $F$-criterion was carried out. Comparison between the experimental and theoretical curves was carried out in all the experimental points, not only in the medium filling range. Statistical evaluation of the adequacy of the model to the experimental results was done by the least squares method.

For this purpose, the Frumkin equation (2) was brought to a linear relationship in the coordinates: $X=\Theta, Y=\ln \{\Theta /[(1-\Theta) C]\}$. The simplest equation of the linear dependence of $Y$ on $X$ is: 


$$
Y=d+b X \text {, }
$$

where $d$ and $b$ are the regression coefficients. Then, the experimental points were plotted on the $X-Y$ plane. Through these points a straight line was drawn so that the sum of deviations of the experimental points to the left and right from that line were about the same. In this way the theoretical curve was obtained. The dispersion of the model adequacy, $S_{\text {ad }}^{2}$, characterizes the deviation of the data $Y_{i}$, calculated by regression equation (5), from the actual experimental results $Y_{i}$ for the $i^{\text {th }}$ point at which they were measured. The sample variance $S_{y}^{2}$ was determined from experimental data as the sum of the variances of each $Y_{i}$ divided by $m(n-1)$, where $m$ is the number of points on the regression line and $n$ is the number of parallel measurements at each point.

Statistical evaluation of the adequacy is made using the $F$-criterion:

$$
F_{\text {exp }}=S_{\text {ad }}^{2} / S_{y}^{2}
$$

with the number of degrees of freedom of the numerator $(m-2)$, and the denominator of $m(n-1)$. The resulting value is compared to tabulated $F_{m, m-2.05}$. If $F_{\text {exp }}<F_{\text {table, }}$, the statistical isotherm is described by this equation with an accuracy of $5 \%$.

To evaluate the applicability of the Temkin equation (3), a linear relationship is represented in the coordinates: $X=\ln C, Y=\Theta$. For the Langmuir equation (7): $X=\ln C$, $Y=\ln [\Theta /(1-\Theta)]$.

If several equations are accepted by Fisher's criterion at $95 \%$, the next problem is to choose one of these equations for a quantitative interpretation of the adsorption isotherms of organic compounds and to compare the adsorption ability of various organic anions.

B.B. Damaskin [26] suggested a criterion to determine which of the three equations describes the experimental curve. That criterion is the position of the minimum in the experimental curve $d \ln C / d \Theta v s$. $\Theta$. In order to determine the attraction constant $a$ in the Frumkin isotherm from the shape of adsorption isotherms, it is necessary to determine the concentration of the organic compound from a plot of $\Theta$ vs. $C$ where $\Theta=0.5$, and then to represent the experimental isotherm in the coordinates $\Theta-y=C / C_{\Theta=0.5}$.

The attraction constant is determined by the equation:

$$
a=[1 /(1-2 \Theta) \ln [(y(1-\Theta)) / \Theta]
$$

Substituting the values of $\Theta$ and $y$ from the experimental $\Theta, y$-curve into this relationship, we obtain a series of attraction constant values from which we can determine the arithmetic mean. Once $a$ is known, we can use equation (2) to determine the value of $B$ for each $\Theta$ and calculate the arithmetic mean. Thus, after the values of adsorption constants $a$ and $B$ have been determined, we can calculate the free energy of adsorption from equation (4).

To test the Temkin equation, we substitute the experimental values of $\Theta$ and $C$ into equation (3), and thus obtain a set of equations. From each of the subsequent equations we 
subtract the previous one, thus we have a set of values of $f$, the energy factor of the surface heterogeneity, and hence we can calculate its arithmetic mean. Knowing the value of $f$, we define the value of $B$ for each $\Theta$ and calculate the average value. Having the value of $f$ and experimental $\Theta$ and $C$, we calculate the value of $B_{\max }$ from equation (3) and the free energy of adsorption by equation (4).

In the case of the Langmuir equation, using the experimental $\Theta$ and $C$ values, it is easy to calculate the value of $B$ and $\left(-\Delta G_{\mathrm{a}}^{0}\right)$ from formula (1).

For comparison with the experimental curve, we calculate the theoretical concentration in each of the three cases, using the values of $a, f$, and $B$ determined above. The theoretical curves are compared with the experimental isotherm in the coordinates $\Theta-$ $\lg C$. The theoretical curve for which the free energy of adsorption $\left(-\Delta G_{\mathrm{a}}^{0}\right)$ is determined with the smallest error is accepted.

The study of passive films on steel was carried out in deaerated borate buffer using the method of galvanostatic coulometry, similarly to the technique described in $[5,6]$. For this purpose, the steel was passivated for 15 minutes at $E=0.2 \mathrm{~V}$ immediately after the cathodic reduction of the primary oxide film, and then the oxide formed was galvanostatically reduced with a current density of $i=9 \mu \mathrm{A} / \mathrm{cm}^{2}$. A phosphonate inhibitor was injected into the solution simultaneously with the imposition of the anodic potential.

\section{Results and discussion}

Although OP is able to transfer steel to a passive state, the formation of a protective film is rather slow. For example, after 15 minutes of exposing a steel electrode to the borate buffer containing $0.01 \mathrm{M} \mathrm{NaCl}$ and $\mathrm{OP}, E_{\mathrm{c}}$ continues to change and its constant value is established only after 2 hours.

If the potential scan is started after $15 \mathrm{~min}$ of exposure, spontaneous passivation of steel does not occurs even in the presence of $4 \mathrm{mmol} / \mathrm{l} \mathrm{OP}$, despite a significant reduction in the passivation current density $i_{\mathrm{p}}$ (Figure 1a). With increasing in time $(\tau)$, passivation occurs at $C=0.3 \mathrm{mmol} / \mathrm{l}$, and the pitting potential $E_{\mathrm{pt}}$ also increases (Figure $1 \mathrm{~b}$ ).

E. Kálmán et al. [15] believe that the slow increase in $E_{\mathrm{c}}$ in neutralized aqueous solutions of alkyldiphosphonates is due to the formation of self-assembled layers on the metal surface, but formation of a mature protective film requires not only prolonged exposure of a specimen in a solution but also some threshold concentration of the inhibitor.

The long time of $E_{\mathrm{c}}$ stabilization in OP solutions allows us to assume that the passivating ability of OP can also be associated with self-organization of protective layers on the surface. Formation of chemical bonds, including those of phosphonate complexes with cations of dissolving metal, is quite a reasonable assumption, but additional studies are required to confirm it. In this context, valuable information can be obtained by in situ ellipsometric measurements of the adsorption of the organic passivating agent. 

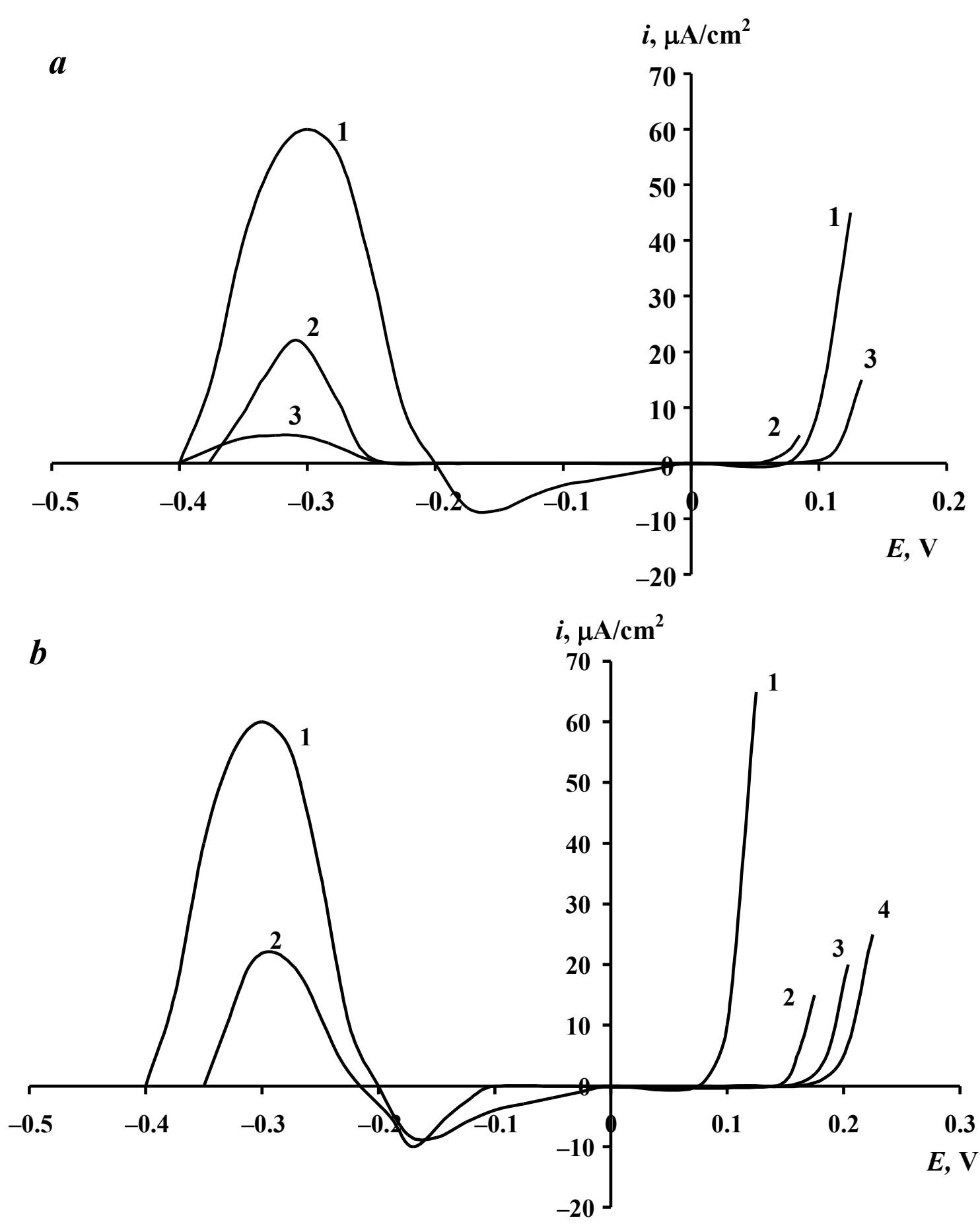

Figure 1. Anodic polarization curves of mild steel in borate buffer solution with $\mathrm{pH} 7.4$ containing $0.01 \mathrm{M} \mathrm{NaCl}$ and $\mathrm{OP}, t=20^{\circ} \mathrm{C}$. a $-\tau=15 \mathrm{~min}, C_{\text {in }}(\mathrm{mmol} / \mathrm{l}): 1-0,2-0.3$, $3-4.0 ; \mathrm{b}-\tau=120 \mathrm{~min}, C_{\text {in }}(\mathrm{mmol} / \mathrm{l}): 1-0,2-0.2,3-0.3,4-4.0$. 
Figure 2a shows the variation of ellipsometric angle $\Delta$ on the logarithm of OP concentration on reduced and oxidized steel surfaces. In essence, these plots are adsorption isotherms, in which the stabilization of a constant angle $\Delta$ in the form of a plateau corresponds to $\Theta=1$. Calculations show that the OP adsorption isotherms can be described by the Frumkin equation (Figure 2b) with the following adsorption energies:

$$
\begin{array}{ll}
\text { at } E=-0.65 \mathrm{~V}: & \left(-\Delta G_{\mathrm{a}}^{0}\right)=36.31 \mathrm{~kJ} / \mathrm{mol} ; a=1.46 ; \\
\text { at } E=0.20 \mathrm{~V}: & \left(-\Delta G_{\mathrm{a}}^{0}\right)=29.63 \mathrm{~kJ} / \mathrm{mol} ; a=1.45 .
\end{array}
$$

OP was adsorbed at higher concentrations on the oxidized steel surface than on the reduced one. The apparent free adsorption energies indicate that $\mathrm{OP}$ can be adsorbed rather strongly both on the reduced and oxidized steel surface, but they do not allow one to conclude on the inhibitor chemisorption.

From this point of view, the effect of temperature on the formation of protective layer deserves more attention. Physical adsorption is usually adversely affected by raising the temperature, while the rate of chemical interactions can increase in this case.

As we noted previously [22], $E_{\mathrm{c}}$ reaches a constant value in 15 minutes at $t=60^{\circ} \mathrm{C}$ after cathodic reduction of the primary oxide and then remains almost unchanged. It is evident from Figure 3 that transition of steel to the passive state required only $0.1 \mathrm{mmol} / 1$ of OP, although the value of $i_{\mathrm{p}}$ in borate buffer is significantly higher than at $t=20^{\circ} \mathrm{C}$. However, at such a low $C_{\text {in }}$ the passive state is not yet stable and $E_{\mathrm{pt}}$ is even more negative than in a solution without the inhibitor where passivation is due to the formation of an oxide film [6]. Apparently, OP is adsorbed on active centers and inhibits the growth of the oxide film, as was observed for its homologue, DDP [19]. If the oxide film becomes thinner, this OP concentration is insufficient to maintain the passive state under conditions of competitive adsorption with chloride that causes pitting.

It is also known that the protective efficiency of phosphonates is essentially affected by hydrodynamic conditions, i.e., the velocity of the medium [6]. Polarization curves of a rotating $(v=0.8 \mathrm{~m} / \mathrm{s})$ disk electrode of mild steel have shown that this is also true for OP (Figure 4). As in the case of temperature rising, the time of $E_{\mathrm{c}}$ stabilization does not exceed 15 minutes on a rotating electrode. Even at $C_{\text {in }}=0.05 \mathrm{mmol} / 1$ there is a significant decrease in $i_{\mathrm{p}}$, and spontaneous passivation of steel takes place with an increase in $C_{\text {in }}$ to $0.3 \mathrm{mmol} / 1$.

Since the OP molecule has a hydrocarbon part, its inhibitive properties will depend to a certain extent on the hydrophobicity of the molecule, which can be quantified by using the logarithm of the partition coefficient of the substance in the octanol-water system $(\log P)$. The $\log P$ value can be obtained both by experimental and calculation methods using the hydrophobicity $f$-constants of substituents [27]. Since the OP molecule is characterized by a positive value of $\log P=1.70$, it has hydrophobic properties. However, in comparison with the passivating corrosion inhibitors of carboxylate type, such as phenylundecanoic acid with $\log P=5.89$, which shows a high protective properties toward mild steel [6], the hydrophobicity of OP is low. This gives OP some advantages in 
environmental context, because according to [28] chemical compounds with $\log P<3.0$ create practically no danger of bioaccumulation by the cells of living organisms.
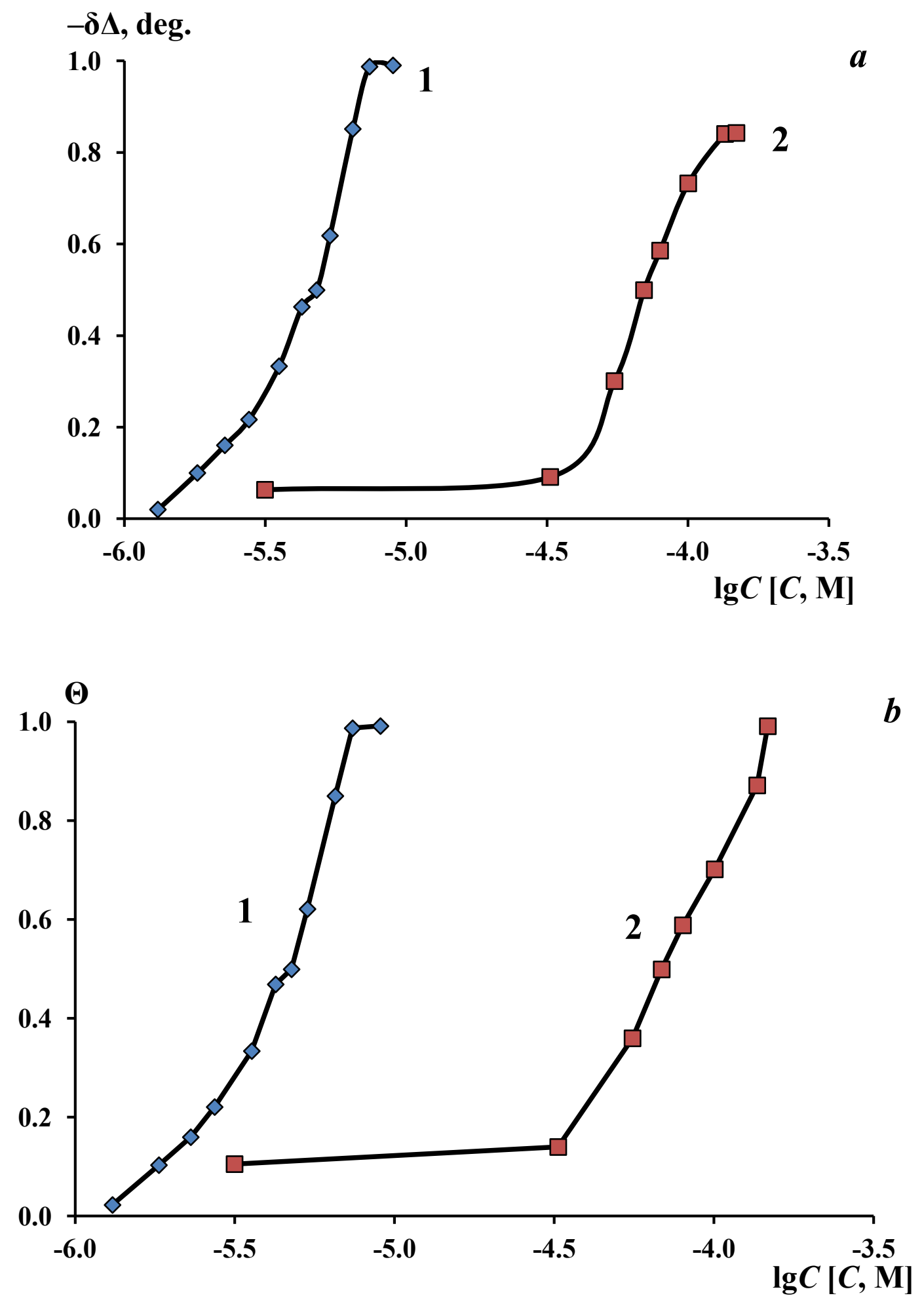

Figure 2. The dependence of ellypsometric angle $\Delta$ (a) and coverage degree $\Theta$ (b) on $C_{\text {in }}$ in borate buffer at $\mathrm{pH} 7.4$ on steel surface reduced at $E=-0.65 \mathrm{~V}$ (1) or oxidized at $E=0.20 \mathrm{~V}$ (2). 


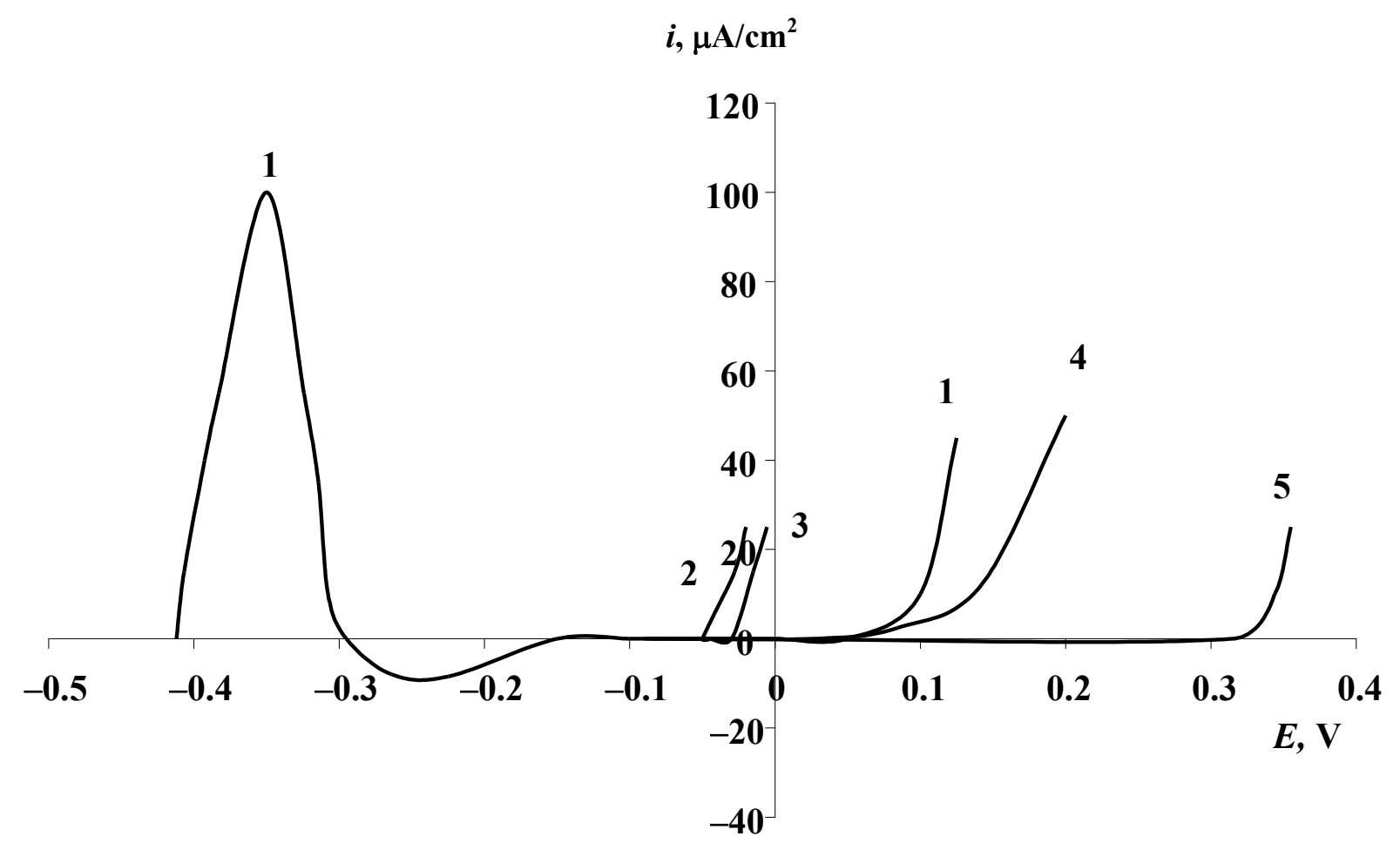

Figure 3. Anodic polarization curves of mild steel in borate buffer solution with $\mathrm{pH} 7.4$ containing $0.01 \mathrm{M} \mathrm{NaCl}$ and OP. $\tau=15 \mathrm{~min}, t=60^{\circ} \mathrm{C}, C_{\text {in }}(\mathrm{mmol} / \mathrm{l}): 1-0.0,2-0.1,3-0.3$, $4-1.0,5-3.0$.

However, the value of $\log P$ characterizes the hydrophobicity of neutral molecules, but for dissociated forms the value of $\log D$ can be used [29], which is $\mathrm{pH}$ dependent and associated with $\log P$ and acidity constant $\left(\mathrm{p} K_{\mathrm{a}}\right.$ ) by the following relationship:

$$
\begin{array}{ll}
\text { for acids } & \log D_{(\mathrm{pH})}=\log P-\log \left[1+10^{(\mathrm{pH}-\mathrm{pKa})}\right] \\
\text { for alkalies } & \log D_{(\mathrm{pH})}=\log P-\log \left[1+10^{(\mathrm{pKa}-\mathrm{pH})}\right]
\end{array}
$$

It is seen from the calculated values of $\log D$ that the hydrophobicity of OP decreases with increasing $\mathrm{pH}$ of the solution:

\begin{tabular}{cccccc}
\hline $\mathrm{pH}$ & 5.0 & 6.0 & 7.4 & 8.0 & 8.7 \\
\hline $\log D$ & -0.53 & -1.37 & -1.90 & -2.13 & -2.49 \\
\hline
\end{tabular}

On the one hand, a decrease in hydrophobicity with $\mathrm{pH}$ increase reduces the surface activity of the compound, on the other - the functional groups are ionized to a greater extent and may be more reactive in the interaction with a positively charged steel surface.

The polarization data obtained in borate solution with $\mathrm{pH} 8.7$ indicate an insignificant change in the protective properties of OP compared to the neutral buffer. The ability of the inhibitor to transfer steel to a passive state cannot be evaluated in a weakly alkaline 
solution, because spontaneous passivation of steel is observed in the absence of an inhibitor (Figure 5). However, displacement of $E_{\mathrm{pt}}$ of steel to positive values allows one to evaluate the role of the time factor in the formation of the passive film.

In short-term exposures, OP does not suppress local depassivation (Figure 5a). At the same time, an increase in the exposure time of the electrode in a solution containing OP to $1.5 \mathrm{~h}$ leads to an $E_{\mathrm{pt}}$ growth (Figure $5 \mathrm{~b}$ ) at $C_{\mathrm{in}}=3 \mathrm{mmol} / \mathrm{l}$.

In [30], an important role of the surface oxide in the formation of a protective OP layer was shown, while the oxide-free surface is less advantageous. At the same time, according to the results of ellipsometric measurements described above, the calculated adsorption energy is higher for the reduced surface. Apparently, the conditions of film formation (potential, composition of the solution, etc.) are also important in the OP adsorption.

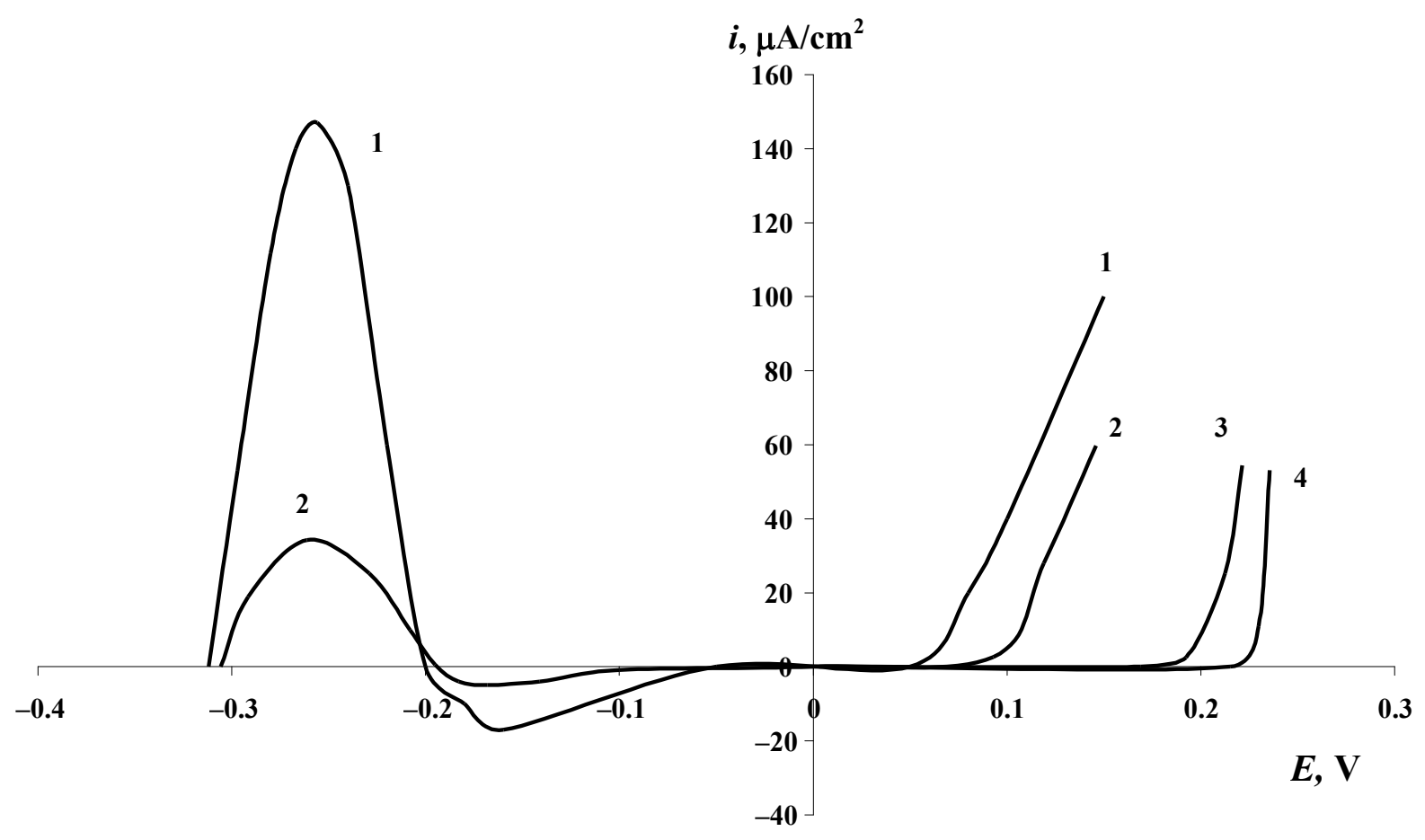

Figure 4. Anodic polarization curves of a rotating disk mild steel electrode in borate buffer solution with $\mathrm{pH} 7.4$ containing $0.01 \mathrm{M} \mathrm{NaCl}$ and $\mathrm{OP}$ (electrode exposure time $-15 \mathrm{~min}$ ), $t=$ $20^{\circ} \mathrm{C}, C_{\text {in }}(\mathrm{mmol} / \mathrm{l}): 1-0,2-0.05,3-0.30,4-0.50$. 

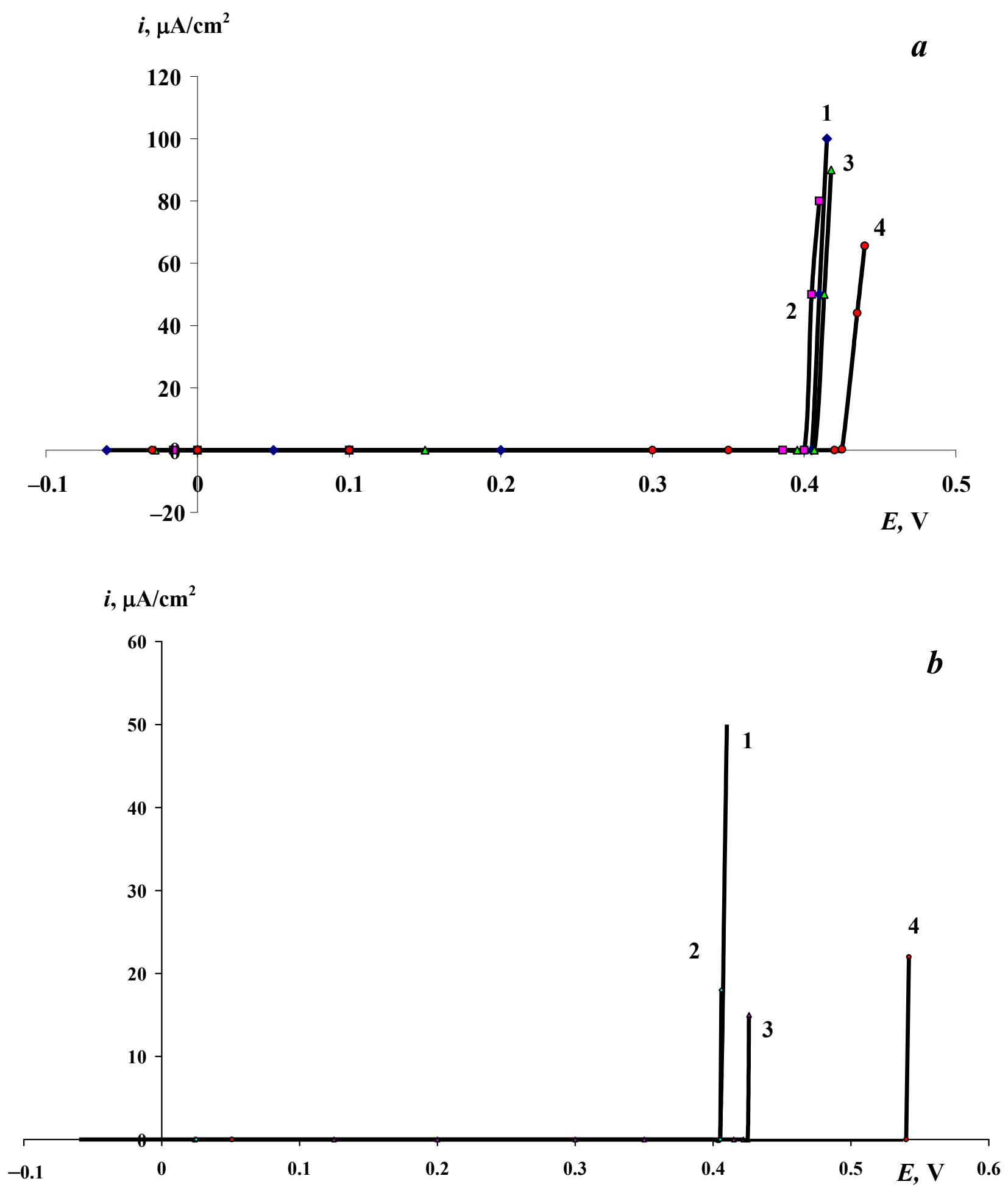

Figure 5. Anodic polarization curves of mild steel in borate buffer solution with $\mathrm{pH} 8.7$ containing $0.01 \mathrm{M} \mathrm{NaCl}$ and $\mathrm{OP}, t=20^{\circ} \mathrm{C}, C_{\mathrm{in}}(\mathrm{mmol} / \mathrm{l}): 1-0.0,2-0.3,3-1.0,4-3.0$. $\mathrm{a}-t=15 \mathrm{~min} ; \mathrm{b}-t=120 \mathrm{~min}$. 
It was shown by the example of DDP [19] that, to achieve steel passivation without formation of a surface oxide, it is necessary to adsorb the inhibitor on the freshly-reduced electrode surface at a cathodic potential. However, it remained unclear whether this condition is required for other alkylphosphonates. For example, it was shown that OP is a more efficient passivating agent than its higher homologues [22].

Therefore, adsorption passivation in the presence of OP can occur under conditions of mild steel corrosion without preliminary formation of ultrathin inhibitor layers. To verify this assumption in our experiments, OP was injected into deaerated borate buffer with $\mathrm{pH} 7.4$ simultaneously with imposition of a potential in the passive range of steel, $E=0.2$ $\mathrm{V}$, on the electrode. After the formation of a passive film, a cathodic current density of $i=$ $9 \mu \mathrm{A} / \mathrm{cm}^{2}$ was imposed on the electrode and time-potential diagrams were obtained (Figure 6).

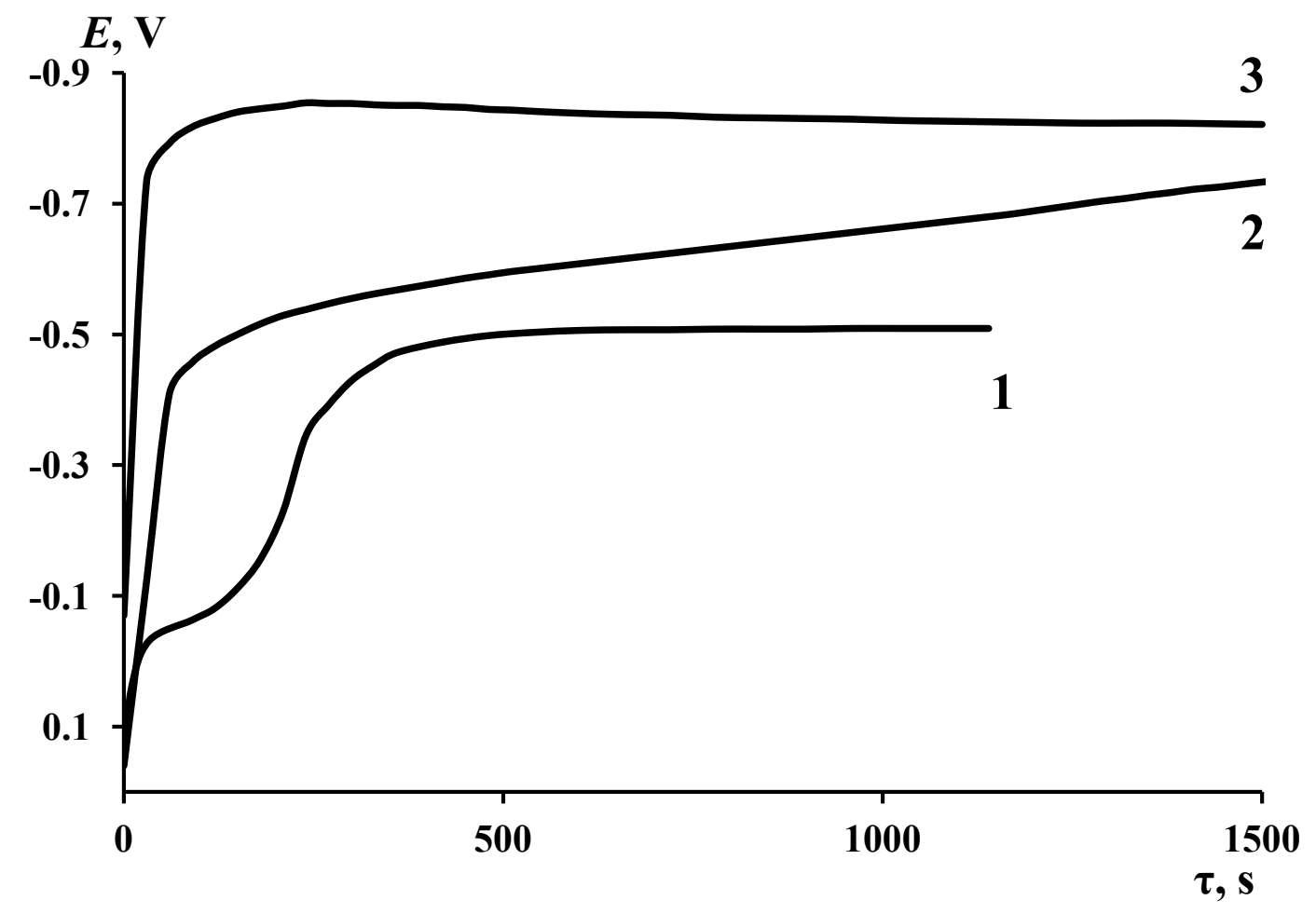

Figure 6. Time-potential diagrams of mild steel in borate buffer solution with $\mathrm{pH} 7.4$ at a constant cathode current density of $9 \mu \mathrm{A} / \mathrm{cm}^{2} . C_{\text {in }}(\mathrm{mmol} / \mathrm{l}): 1-0,2-0.5,3-1.0$.

In the absence of OP, a delay is observed on the time-potential curve in the potential region of $E=-0.05$ to $-0.23 \mathrm{~V}$, which is associated with the reduction of surface oxides. In the presence of 0.5 and $1.0 \mathrm{mmol} / 1$ of OP, the delay disappears and the overvoltage of the hydrogen evolution reaction increases. Thus, OP is able to protect steel by the "nonoxide" passivation mechanism where the adsorption of the organic inhibitor plays a major role. 


\section{Conclusions}

The passivating ability of OP depends on the time of exposure of the electrode to the solution. Rising in temperature and stirring the solution facilitate the formation of protective layers on steel by the phosphonate. Upon formation of protective layers, OP inhibits the growth of the surface oxide on steel up to the realization of the "non-oxide" passivation. The adsorption of OP on the oxidized and reduced surface of the steel can be described by the Frumkin equation. On reduced steel surface, OP is adsorbed much better then on the oxidized one.

\section{References}

1. D.M. Brasher, Symposium Europeen sur les Inhibiteurs de Corrosion, Ferrara (Italie), 1960, p. 313.

2. D.E. Davis and Q.J.M. Slayman, Corros. Sci., 1971, 10, 671.

3. J.E.O. Mayne and C.L. Page, Br. Corros. J., 1974, 9, 223.

4. I.L. Rozenfel'd, Yu.I. Kuznetsov, I.Ya. Kerbeleva and V.P. Persiantseva, Prot. Met., 1975, 11, 612.

5. Yu.I. Kuznetsov, I.L. Rozenfel'd, I.Ya. Kerbeleva, E.V. Naydenko, N.N. Balashova, Prot. Met., 1978, 14, 253.

6. Yu.I. Kuznetsov, Organic Inhibitors of Corrosion of Metals, Plenum Press, New York, 1996, $283 \mathrm{pp}$.

7. Yu.I. Kuznetsov, Russ. J. Electrochem., 2004, 40, 1287.

8. Yu.I. Kuznetsov, Prot. Met. Phys. Chem. Surf., 2011, 47, 745.

9. Yu.I. Kuznetsov, Int. J. Corros. Scale Inhib., 2016, 5, no. 4, 282. doi: 10.17675/23056894-2016-5-4-1

10. R. Subramanian and V. Lakshminarayanan, Corros. Sci., 2002, 44, 535.

11. Yu.I. Kuznetsov, M.O. Agafonkina, H.S. Shikhaliev, N.P. Andreeva and A.Yu. Potapov, Int. J. Corros. Scale Inhib., 2014, 3, no. 2, 137. doi: 10.17675/2305-6894-2014-3-2$\underline{137-148}$

12. I. Milošev, N. Kovačević, J. Kovač and A. Kokalj, Corros. Sci., 2015, 98, 107.

13. I. Milošev, N. Kovačević, J. Kovač and A. Kokalj, Corros. Sci., 2015, 98, 457.

14. J.S. Gill, Development of Scale Inhibitors. In the book: Reviews on Corrosion Inhibitor Science and Technology, NACE, Houston, 1996, X-1-20.

15. I. Felhősi, E. Kálmán and P. Póchik, Russ. J. Electrochem., 2002, 38, 230.

16. Yu.I. Kuznetsov, G.Yu. Kazanskaya and N.V. Tsirulnikova, Prot. Met., 2003, 39, 120.

17. I. Felhősi, Ju. Telegdi, G. Palinkas and E. Kálmán, Electrochim. Acta, 2002, 47, 2335.

18. A. Paszternák, S. Stichleutner, I. Felhősi, Z. Keresztes, F. Nagy, E. Kuzmann, A. Vértes, Z. Homonnay, G. Pető and E. Kálmán, Electrochim. Acta, 2007, 53, 337.

19. I.D. Zartsyn, V.B. Shchukin and Kh.S. Shikhaliev, Prot. Met. Phys. Chem. Surf., 2010, 46, 775 . 
20. S. Attavar, M. Diwekar, M.R. Linford, M.A. Davis and S. Blair, Appl. Surf. Sci., 2010, 256, 7146.

21. T. Abohalkuma, F. Shawish and J. Telegdi, Int. J. Corros. Scale Inhib., 2014, 3, no. 3 , 151. doi: $10.17675 / 2305-6894-2014-3-3-151-159$

22. A.A. Chirkunov, A.S. Gorbachev, Yu.I. Kuznetsov and Kh.S. Shikhaliev, Korroz.: mater., zashch., 2010, no. 6, 22 (in Russian).

23. N.P. Andreeva, Korroz.: mater., zashch., 2007, no. 2, 41 (in Russian).

24. N.P. Andreeva and Yu I. Kuznetsov, Prot. Met., 1987, 13, 601.

25. N.P. Andreeva and Yu. I. Kuznetsov, Prot. Met., 1989, 25, 214.

26. B.B. Damaskin, O.A. Petriy and V.V. Batrakov, Adsorption of organic compounds on electrodes, Nauka, Moscow, 1968, 334 pp. (in Russian).

27. C. Hanch and A. Leo, Substituent Constants for Correlation Analysis in Chemistry and Biology, Wiley-Interscience, New York, 1979, 339 pp.

28. W.W. Frenier, Proceedings of the $9^{\text {th }}$ European Symp. on Corros. Inhibitors, Ferrara (Italy), 2000, 1-30.

29. R.A. Scherrer and S.M. Howard, J. Med. Chem., 1977, $20,53$.

30. A. Paszternák, I. Felhősi, Z. Pászti, E. Kuzmann, A. Vértes, E. Kálmán and L. Nyikos, Electrochim. Acta, 2010, 55, 804. 